BULLETIN Bulletin hispanique

HISPANIQUE Université Michel de Montaigne Bordeaux

122-1 | 2020

Variations donjuanesques

\title{
Luis de Góngora, Sonetos
}

Madrid, Cátedra, Letras Hispánicas, 818, 2019

\section{Óscar García Fernández}

\section{OpenEdition}

Journals

Edición electrónica

URL: http://journals.openedition.org/bulletinhispanique/11001

DOI: 10.4000/bulletinhispanique. 11001

ISSN: 1775-3821

Editor

Presses universitaires de Bordeaux

Edición impresa

Fecha de publicación: 18 junio 2020

Paginación: 351-354

ISBN: 979-10-300-0592-9

ISSN: 0007-4640

Referencia electrónica

Óscar García Fernández, «Luis de Góngora, Sonetos», Bulletin hispanique [En línea], 122-1 | 2020,

Publicado el 18 junio 2020, consultado el 19 enero 2021. URL: http://journals.openedition.org/

bulletinhispanique/11001; DOI: https://doi.org/10.4000/bulletinhispanique.11001

Este documento fue generado automáticamente el 19 enero 2021.

Tous droits réservés 


\title{
Luis de Góngora, Sonetos
}

\author{
Madrid, Cátedra, Letras Hispánicas, 818, 2019 \\ Óscar García Fernández
}

\section{REFERENCIA}

Luis de Góngora, Sonetos, Edición de Juan MATAS CABALLERo, Madrid, Cátedra, Letras Hispánicas, 818, 2019, 1740 pp.

1 En lengua castellana, uno de los mejores cultores de la difícil forma del soneto fue don Luis de Góngora. Este tipo de composición de origen itálico constituye, por su brevedad y carácter, un verdadero tour de force, una pieza de ingeniería literaria en la que no ha de faltar, ni sobrar nada. En el corpus que conforman los doscientos doce sonetos de Góngora se integran varias obras maestras, que hoy podemos aprehender en todo su brillo y complejidad gracias a la extraordinaria edición cuidada por Juan Matas Caballero, uno de los más autorizados especialistas en la poesía del Siglo de Oro.

2 La preparación de este opus magnum de la Filología Hispánica le ha llevado más de una década de paciente labor investigadora al profesor Matas, aunque a la vista del fruto ya impreso puede afirmarse sin ambages que la espera ha merecido la pena. En efecto, nos encontramos ante una edición modélica tanto en el plano ecdótico como en el plano de la anotación y comentario de cada texto. El encomiable trabajo cumple su primer objetivo a la perfección: presentar de la forma más depurada posible los textos y acercarse tanto como sea posible al estado en que Góngora los concibió. Para dilucidar una profusa serie de textos marcada indeleblemente por la brevedad y la complejidad, la presente edición incluye una exhaustiva serie de anotaciones y commenti que no dejan hueco sin cubrir, ni duda sin aclarar.

3 Estamos ante una edición grandiosa en todos sus aspectos. Por un lado, es magna en el plano meramente material: desde el número de páginas que integran el tomo (mil setecientas cuarenta) hasta el tamaño mismo de la caja (considerablemente mayor que el de los otros libros que integran la colección Letras Hispánicas). Además, desde el punto de vista del contenido, resulta grandiosa por la erudición, trabajo y 
sistematización que propone de los sonetos, situando, sin duda, esta edición como la canónica para citar estos poemas.

Esta sublime edición está muy bien pensada desde el inicio dado que comienza con una Introducción de casi doscientas cincuenta páginas dividida en dos bloques: un estudio en el que se incluye una clasificación de los sonetos y un análisis de la lengua poética; y un amplio apartado dedicado a la Bibliografía. El éxito de esta Introducción se asienta en que se nos ofrecen unas claves concisas para interpretar de la manera más adecuada estos poemas y se nos proporciona una bibliografía muy completa, estructurada y organizada.

Respecto a la clasificación de las piezas, el editor se decanta por ordenar los sonetos de manera diacrónica, ya que ni Góngora hizo nunca un cancionero ni sus propios editores estaban de acuerdo al proponer una taxonomía temática. Matas hace un recorrido por otras ediciones previas de los sonetos como las de Ciplijauskaité o de la poesía de Góngora como la de A. Carreira. Es, además, muy interesante el recorrido por la historiografía critica, con Ena Victoria Thomas y su clasificación genérica y temporal, pasando a la más interesante de Giulia Poggi, cuya utilidad es reconocida por el editor, pero intenta mejorarlas para aclarar más y mejor la producción gongorina.

Dado que el cordobés no publicó sus obras en vida y circularon de manera manuscrita en muchos y muy diferentes testimonios, el editor utiliza como texto base para el cotejo el afamado manuscrito Chacón en la mayoría de los sonetos. Junto a esto, un elemento muy relevante que Matas Caballero pondera es la relación de estos sonetos con el resto del corpus gongorino, haciendo hincapié en la interesante officina poetica que supusieron los sonetos para el resto de su obra, especialmente para sus poemas mayores.

De manera acertada, el profesor Matas nos acerca a la vida del poeta en las aclaraciones de cada soneto, permitiéndonos ver así la evolución del autor y el hilo conductor diacrónico-ideológico de las cuatro partes en que divide su obra:

8 I (1582-1586): incluye sus primeros sonetos, es una etapa muy manierista y de temática amorosa principalmente, con un petrarquismo llevado al extremo y una gran perfección formal, donde, además, señala las fuentes de la imitatio gongorina;

II (1588-1608): se adentra en un mundo plenamente barroco y amplía los temas con presencia de los sonetos heroicos (definido en las págs. 28-30) y lo satírico y burlesco tras sus visitas a la corte vallisoletana y madrileña;

10 III (1609-1616): destacan los sonetos fúnebres, laudatorios y los satíricos y burlescos, donde se observa el desengaño que vivió el poeta durante su vida cortesana o sus batallas literarias contra Lope o Quevedo;

11 IV (1617-1624): el Góngora de senectute vuelve a la corte, marcado por la pobreza y sus deseos de seguir ampliando horizontes.

12 También la parte del estudio dedicado a la lengua poética resulta muy interesante y sugestiva. Antes de comenzar su análisis, Matas nos presenta una breve pero útil recepción crítica del estilo de Góngora.

13 En este apartado, Matas nos ofrece una gran erudición, pero no es gratuita, sino que está al servicio de clarificar las claves estilísticas, que se centran en los cultismos léxicos y sintácticos, el uso de sintagmas y expresiones, así como las perífrasis, deteniéndose en los tópicos literarios, las alusiones mitológicas, la presencia de la emblemática y las metáforas. Además, a modo de conclusión, el doctor Matas pondera 
la excelsa calidad de los sonetos gongorinos, "que ofrecen no pocas claves de su estilo y personalidad" (p. 86).

14 La erudición y el trabajo extenso e intenso que hace el profesor Matas también se puede observar en el apartado relativo a la Bibliografía. No es baladí que nos encontremos sesenta páginas en las que se describen de manera detallada manuscritos e impresos que contienen sonetos gongorinos, incluyendo la nueva numeración de los sonetos al final de cada testimonio. Llama la atención la cantidad de testimonios consultados, mayor el número de manuscritos frente a los impresos, lo que pone de manifiesto un arduo trabajo de búsqueda y cotejo. Si le sumamos la presencia de varias portadas de testimonios, la descripción alcanza una eminente singularidad. actualiza el texto según las normas de la RAE, dejando solo las grafías con valor fonético y fonológico, otro acierto que facilita la lectura. Así, cotejar todas estas ediciones y depurar la obra gongorina es un objetivo cumplido con éxito en esta edición.

Otro elemento para destacar es la cuantía de las referencias bibliográficas, que ocupan cerca de ciento cincuenta páginas $\mathrm{y}$, en su afán didáctico, las clasifica según criterios muy interesantes, ya que podemos encontrar desde ediciones modernas, estudios gongorinos, otros estudios sobre el Siglo de Oro o la propia poesía, hasta los interesantes comentaristas (más o menos contemporáneos) del poeta cordobés.

17 Pero si la Introducción es de una calidad y utilidad excelsas, el análisis de cada soneto es una maravilla que nos ofrece tres partes bien diferenciadas y sistematizadas: una introducción al soneto, el soneto y la anotación crítica y erudita:

18 Por un lado, en la introducción encontramos una presentación del soneto con su título, número en la serie y año de escritura. A continuación, en esta explicación de las circunstancias históricas y culturales del soneto, Matas destaca a los principales comentaristas del poema, tanto contemporáneos a Góngora como posteriores. Tras comentar brevemente y ponernos en la pista de estos estudios, el editor continúa con un análisis de las fuentes que bebió Góngora, donde se puede observar una gran erudición, un manejo de las fuentes italianas y españolas que, incluso, cita completamente. Es decir, su editor no guarda nada y nos permite leer a Góngora en toda su amplitud, con todas las claves interpretativas en torno a cada soneto.

19 Además, para cerrar esta primera parte introductoria, incluye una serie de referencias bibliográficas centradas en el propio siglo XVII o más actuales; estas referencias son muy útiles filológicamente, ya que permiten un recorrido rápido por la recepción crítica del poema desde los tiempos del propio Góngora.

Otro apartado que cierra esta primera parte y que me parece muy útil es la relación que hace de los distintos epígrafes bajo los que podemos encontrar el mismo poema en otros manuscritos e impresos. De esta manera logra desambiguar las posibles dudas a la hora de atribuir el soneto al autor, otro más de sus grandes aciertos. En este sentido, Matas fija de manera concluyente los sonetos que son de Góngora, pero que hasta ahora solo estaban atribuidos al cordobés.

21 A continuación, dedica una página completa al texto del soneto con el número, el año y el epígrafe o título del mismo. Así, atinadamente, podríamos leer el soneto sin ningún tipo de aclaración.

22 Y en tercer lugar, reencontramos la anotación textual y erudita: en la textual vemos las variantes de los diferentes testimonios y Matas nos presenta también un recorrido por 
los textos donde se encuentra el soneto correspondiente; en la parte erudita dedica una o varias páginas a comentar y explicar verso a verso el contenido del poema. Si en la parte previa el profesor Matas muestra erudición, en esta anotación nos ofrece un análisis detallado verso a verso, ofreciéndonos bibliografía sobre otras obras de Góngora, sobre mitos, referencias a otros poetas... Un modelo de anotación en todos los sentidos; es decir, todo un afán de conocimiento, interés didáctico y deseo de profundidad que queda muy claro gracias a las notas.

En conclusión, una obra que pasa a la historia de la filología tanto por la calidad literaria de los sonetos de Góngora como por la edición del profesor Matas Caballero, quien demuestra un conocimiento de la poesía de nuestros Siglos de Oro que traspasa fronteras, ofrece un análisis en el que no quedan huecos por cubrir y selecciona de manera adecuada la información para ponernos en la pista de la crítica literaria del propio soneto, tanto la contemporánea de Góngora como la más actual.

Esta edición nos ofrece un trabajo inmenso, donde se puede observar una maduración de cada idea, una reflexión profunda, pero desde la absoluta claridad, ya que su objetivo es que comprendamos los sonetos del cordobés. Gracias a una potente introducción, una completísima bibliografía, una edición crítica anotada en positivo, una parte erudita y una anotación filológica, Juan Matas Caballero logra actualizar y aclarar la obra gongorina.

En definitiva, una edición cuya arquitectura es un modelo de trabajo investigador que nos permite transitar por la vida y obra de don Luis con una meridiana claridad, que, incluso, nos deja la oportunidad de leer el soneto sin más indicación que la del año y el título, o tal vez fijándonos solo en la anotación erudita, o nos invita a una fiesta filológica donde leemos, aprendemos y comprendemos unos textos que nos van a permitir no hablar nunca más de Góngora como culterano o «Príncipe de las tinieblas», sino de un Góngora que se entiende y comprende y que dialoga con la historia de la literatura en letras doradas.

\section{AUTORES}

\section{ÓSCAR GARCÍA FERNÁNDEZ}

Universidad de León 